\title{
Suicidal attempt with intracranial sewing needle in a female adult with major depressive disorder, case report
}

\author{
Nima Derakhshan ${ }^{1}$ (D), Shekoofeh Yaghamei $^{2^{*}}$ (D) and Nejla Mostafeenezhad ${ }^{3}$ (D)
}

\begin{abstract}
Background: Major depressive disorder is one of the most common psychiatric illnesses. It is counted as an important suicide-attempting factor. Beside common and known suicide methods such as pesticide poisoning and hanging, some unusual methods (adapted by major depressive disorder patients) are reported in the literature. One of these methods is intracranial swing needle insertion.

Case presentation: Hereby, we detail a 44-year-old woman who was admitted to our hospital due to a sewing needle in her brain tissue. The first sign suggesting the existence of a metal foreign body in her brain was the rejection of magnetic resonance imaging ordered (follow-up of a previous admission). Later, a sewing needle was observed in her skull inserted in a suicidal attempt. Her denial of the attempt has aroused the medical team attention to make further study of the patient from a psychiatric point of view. The psychiatric study expressed major depressive disorder in the patient which can justify her suicide intention in the needle insertion.

Conclusions: Treating such patients should be tackled in two fronts. From neurosurgical point of view, it should be decided whether to extract the foreign body or conduct a follow-up in order to determine the necessary time for operation. On the other hand, from a psychiatric point of view, rigorous consult sessions with patient and family members are required to prevent recurrence of such attempts.
\end{abstract}

Keywords: Case report, Intracranial sewing needle, Major depressive disorder, Rare suicidal attempt

\section{Background}

Major depressive disorder (MDD) is a common psychiatric illness affecting $6-8 \%$ of the world's population. It is accompanied by notable mortality, morbidity, costs, and increased suicide risk [1]. MDD can cause abnormalities that affect mood, neurovegetative functions, psychomotor activity, and cognition. According to the worldwide epidemiological studies, MDD has an estimated lifetime prevalence in the range of $3-6 \%$ in Asia and as high as $12-16 \%$, in western communities [2].

Since 2008, suicide has ranked as the 10th death cause in the USA. In 2016, suicide became the second leading

\footnotetext{
* Correspondence: yaghmaei.shekoofeh@gmail.com

${ }^{2}$ Department of Pediatrics, Namazi Hospital, Shiraz University of Medical

Science, Namazi Square, Shiraz 71937-11351, Iran

Full list of author information is available at the end of the article
}

cause of death for ages $10-34$ and the fourth for ages 35-54 [3].

Almost $90 \%$ of suicides are associated with mental illnesses, particularly MDD [4]. Depression-related suicide rates and the most common suicidal methods vary across countries. For instance, pesticide poisoning is the most common suicidal method in Asian countries and Latin America. Drug poisoning is common in Nordic countries and the UK. Hanging is preferred method in eastern Europe, as is firearm in the USA and jumping from high places in China [5].

Mental disorders not only cause a notable risk for suicide but also lead to homicide and abuse. Intracranial insertion of needle is a rare but well-known homicide attempt threatening the lives of victims, especially infants. Up to 2007, there were about 50 cases reported in

\section{Springer Open}

(- The Author(s). 2020 Open Access This article is licensed under a Creative Commons Attribution 4.0 International License, which permits use, sharing, adaptation, distribution and reproduction in any medium or format, as long as you give appropriate credit to the original author(s) and the source, provide a link to the Creative Commons licence, and indicate if changes were made. The images or other third party material in this article are included in the article's Creative Commons licence, unless indicated otherwise in a credit line to the material. If material is not included in the article's Creative Commons licence and your intended use is not permitted by statutory regulation or exceeds the permitted use, you will need to obtain permission directly from the copyright holder. To view a copy of this licence, visit http://creativecommons.org/licenses/by/4.0/. 
the literature, mostly in Iran and Turkey [6]. Herein, we present an extremely rare case of suicidal attempt with intracranial needle in an adult suffering from MDD.

\section{Case presentation}

\section{Participant(s)}

The patient was a 44-year-old female. She had been a known case of MDD (for 7 years), hypothyroidism, and hyperlipidemia. She had been taking several courses of different anti-depressant medications. However, the treatment was accompanied with poor compliance. She had quit taking her medications for a year prior to her first admission.

\section{Process}

\section{First admission}

She was admitted to neurosurgery ward with seizure and right lower extremity weakness. Gadolinium-enhanced brain magnetic resonance imaging (MRI) revealed a right fronto-parietal epidural brain abscess with slight mass effect over right motor cortex. According to her claim, it happened when she accidentally hit her head to a cabinet door. Physical examination revealed a crust over a scalp wound near vertex, muscle force of 4 from 5 in her left upper extremity, and no fever. The normal behavior of the patient herself and her family did not raise any suspicion for an underlying psychiatric condition. She received anticonvulsants and antibiotics for 8 consecutive weeks afterward. She was discharged with complete recovery from neurological problems. She was requested to attend for a follow-up visit within the following month with a new gadolinium-enhanced MRI.

\section{Follow-up visit}

A month later, we received a notification from MRI department that this patient could not undergo MRI due to an intracranial metallic object. Accordingly, a skull Xray and contrast-enhanced spiral computed tomography (CT) scan was requested which revealed, respectively, a metallic object near the vertex (Fig. 1a) and a left paramidline entry without injury to any major vessel in the coronal view (Fig. 1b).

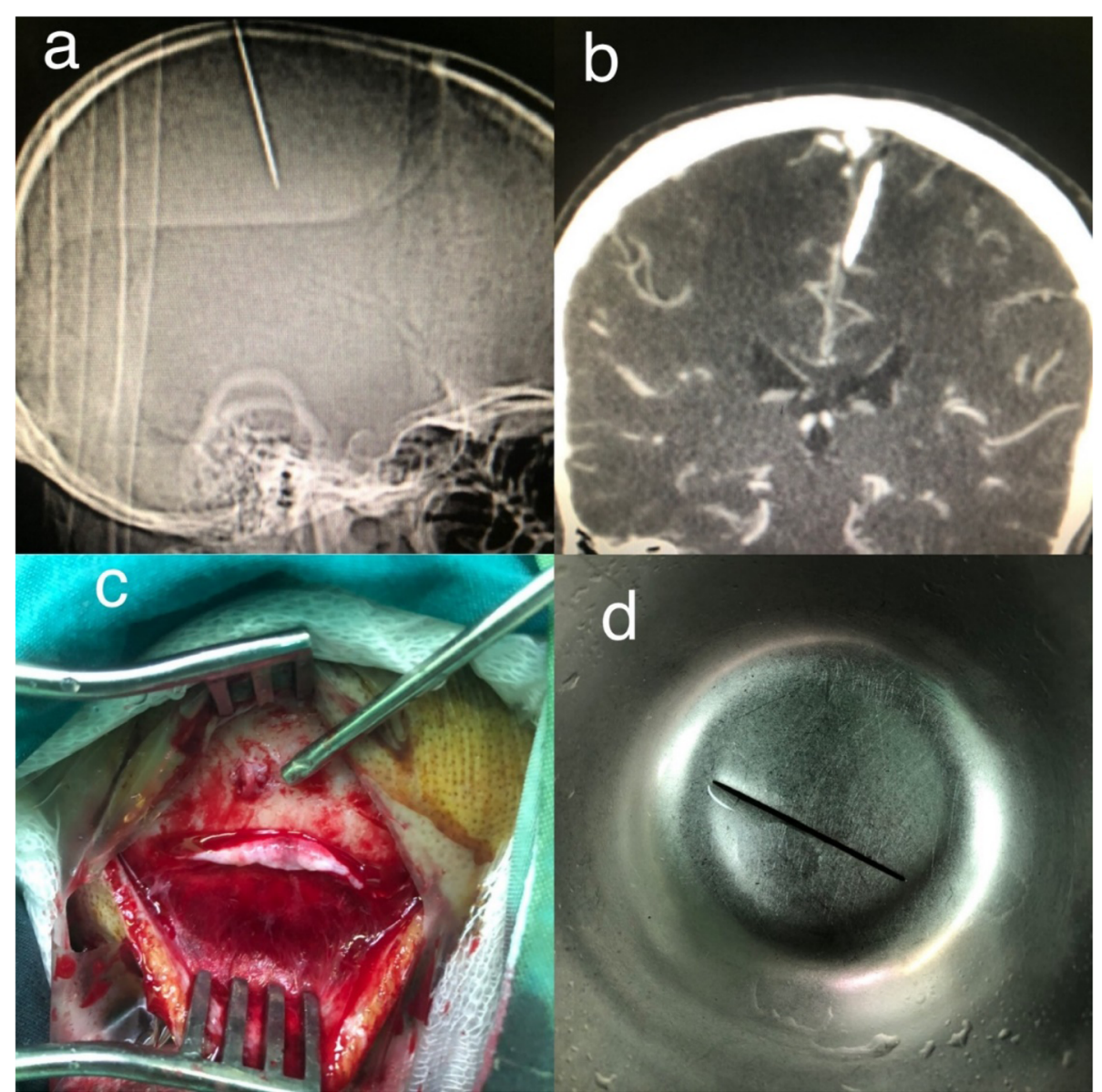

Fig. 1 a Plain lateral skull X-ray (a metallic object entering near vertex). b Coronal view of contrast-enhanced brain CT scan (the trajectory of an intra-cranial sewing needle) $\mathbf{c}$ Intra-operative exposure of the needle entry point. $\mathbf{d}$ Removed needle covered in black rust 
The patient was admitted urgently for further work-up and extraction of the foreign body. This time, the abnormalities in the reactions such as patient's persistent crying and contradiction in her husband's answers hinted for an underlying psychiatric illness.

\section{Second admission}

Patient was admitted in neurosurgery unit. During the pre-operative work-up, an emergency psychiatrist consultation was requested. According to the psychiatric evaluation, in spite of having a "rich" history of psychiatric problems, she was not treated in a well fashion, i.e., she did not take proper medications. She also had a suicidal attempt 2 years ago (drug poisoning). However, then, she had refused to be admitted to the psychiatry hospital for a thorough evaluation and treatment.

Patient's neurologic exam was unremarkable, except for a dimple-like fistula at the site of needle entry over left parietal scalp. In addition, her hospital anxiety and depression scale (HADS) scores approved severe anxiety (score 17) and severe depression (score 19).

\section{Surgical intervention}

After placing the patient's head on a horseshoe head rest, general anesthesia was induced. Then, a lazy Sshaped skin incision was made above vertex with the entry site in the middle. The needle was grasped and gently removed (Fig. 1c, d) without the need for any craniotomy.

\section{Psychiatric evaluation and treatment}

After surgery, patient was transferred to the psychiatry department for further evaluation. She was admitted in psychiatric department for 3 weeks. During her admission there, she had consultation sessions twice per week. Despite some incoherency in her statements, psychologic assessment revealed that she committed the suicide attempt due to loneliness and family and financial problems.

The patient did not state any sign of psychosis such as delusion, hallucination, or over-valued ideas while she was observed. In addition, she had no history of drug abuse. The most prominent symptoms in the patient were obvious isolation and apathy.

Meanwhile, she received $50 \mathrm{mg}$ per day of sertraline and $20 \mathrm{mg}$ perphenazine every night as well as $8 \mathrm{ECT}$ sessions. The patient was discharged from the hospital after 3 weeks as she did not have any suicide idea and her symptoms were controlled. The patient was prescribed to continue the mentioned medications and requested to do a follow-up in 1 month.

\section{Discussion}

MDD patients have a great potential to commit suicide. Accordingly, it is highly important for psychiatrics to adapt proper treatments to minimize these patients' suicide risk. According to the literature, odd and unique suicide attempts, e.g., intracranial needle insertion, are more common in psychotic patients [7]. Some cases of intracranial needle insertion are presented in Table 1. As noted in Table 1, in most of the reported intracranial needle insertions, it is unclear how the insertion happened. Needles' location in many cases suggests that the needles were inserted (either intentionally or unintentionally) through the anterior fontanel during infancy, when the fontanel used to be open.

Intracranial sewing needle has also been reported as an attention-seeking behavior. In addition, it has been reported as a mean of torturing or harming others in case of personality disorders. A thorough psychiatric evaluation and several psychologic assessment sessions of patient and family members are necessary to diagnose the underlying psychiatric condition and apply the suitable treatment protocol accordingly. Effective long-term treatment needs the cooperation between patients' family with the therapy team, and thus, family conflicts and low socio-economic state may jeopardize the treatment process.

Immediate treatment with electroconvulsive therapy (ECT) is usually preferable while waiting for the medication to take effect in case of MDD patients who have made self-harm attempts. However, a long-term maintenance period of medical therapy and patient and family counseling are required to decrease the possibility of attempt's recurrence.

Intracranial needle insertion has not been so common. In addition, the patients were presented with diverse symptoms (based on cases presented in Table 1). These make the diagnosis rather difficult. Different imaging methods such as CT scan can play a crucial role in diagnosis.

In a neurosurgical point of view, metallic foreign bodies are well-tolerated by brain tissue. The incidence of symptoms such as headache, seizure, neurologic deficit, and future brain abscess is relatively rare [8]. A fibrous capsule, containing deposits of porous and flaky iron rust, covers the surface of the needle. This can prevent inflammatory reaction and abscess formation [9].

However, symptomatic cases or cases with a confirmed neurovascular injury should be approached with surgical removal of the foreign body [10]. We also recommend surgical removal in young patients and those with psychiatric conditions. Surgical needle removal can help patients with psychiatric problem to release them from their probable high stress level caused by the anticipation of becoming symptomatic. 
Table 1 Brief review of intercranial foreign body reported cases

\begin{tabular}{|c|c|c|c|c|c|c|c|c|}
\hline \multirow[b]{2}{*}{ Case No. } & \multirow{2}{*}{$\begin{array}{l}\text { Year } \\
\text { reported }\end{array}$} & \multicolumn{3}{|c|}{ Gender } & \multirow[b]{2}{*}{ Signs/Symptoms } & \multicolumn{3}{|c|}{ Reason } \\
\hline & & Age & $\mathrm{F} \square$ & $M^{*}$ & & $\mathrm{H}^{\diamond}$ & $s^{\dot{i}}$ & $u^{\ddagger}$ \\
\hline 1 & 2018 & 21 & & & Slight right hemiparesis & & & \\
\hline 2 & 2017 & 61 & & & Slight dizzy for 2 days & & & \\
\hline 3 & 2016 & 48 & & & Intermittent headaches for one month & & & \\
\hline 4 & 2016 & 25 & & & Absence seizure & & & \\
\hline 5 & 2015 & 4 & & & Fell down accidentally, presented with scalp laceration & & & \\
\hline 6 & 2015 & 56 & & & Generalized tonic colonic seizure & & & \\
\hline 7 & 2014 & 14 & & & Generalized tonic colonic seizure & & & \\
\hline 8 & 2012 & 52 & & & Status epilepticus & & & \\
\hline 9 & 2008 & 10 & & & $\begin{array}{l}\text { Brain abscess and headache and nausea and abnormal } \\
\text { electroencephalogram }\end{array}$ & & & \\
\hline 10 & 2005 & 45 & & & $\begin{array}{l}\text { After car accident a brain CT scan was done and a needle was } \\
\text { accidently found }\end{array}$ & & & \\
\hline $\begin{array}{l}\text { presented } \\
\text { case }\end{array}$ & 2019 & 44 & & & $\begin{array}{l}\text { Symptoms were denied. (The needle was discovered in a follow- } \\
\text { up CT scan shown Figure 1) }\end{array}$ & & & \\
\hline
\end{tabular}

\section{Conclusion}

Intracranial sewing needles may present as a self-harm or suicide attempt in MDD patients. The treatment process includes two major aspects which are:

I. extracting the foreign body in a neurosurgical operation,

II. prevention of the suicide attempt recurrence (including ECT, medications, and counseling sessions).

The whole treatment process (in order to be effective) needs cooperation between neurosurgery and psychiatry teams.

\section{Abbreviations}

MDD: Major depressive disorder; MRI: Magnetic resonance imaging; CT: Computed tomography; HADS: Hospital anxiety and depression scale; ECT: Electroconvulsive therapy

\section{Acknowledgements}

N/A

\section{Authors' contributions}

ND was the neurosurgeon who has operated the patient and presented the case. SY conducted the literature review and wrote the manuscript. NM carried out the psychiatric examinations and provided psychiatric insights into the paper. All authors have read and approved the final version of manuscript.

\section{Funding}

No funding was received to conduct this research work and in preparing the manuscript.

\section{Availability of data and materials} N/A

\section{Ethics approval and consent to participate}

The authors warrant that the work has not been published before in any form except as a preprint, that the work is not being concurrently submitted to and is not under consideration by another publisher, that the persons listed above are listed in the proper order and that no author entitled to credit has been omitted, and generally that the author has the right to make the grants made to the Publisher complete and unencumbered.

\section{Consent for publication}

The patient has given us her consent to publish her treatment details as well as MRI, CT scan, and X-ray images taken in her treatment procedure. The consent form (filled and signed by the patient) is in Persian language. Should the Journal require it, it will be tendered along with its translation to English.

\section{Competing interests}

All authors declare that they have no financial or non-financial competing interests.

\section{Author details}

${ }^{1}$ Department of Neurosurgery, Shiraz University of Medical Science, Shiraz, Iran. ${ }^{2}$ Department of Pediatrics, Namazi Hospital, Shiraz University of Medical Science, Namazi Square, Shiraz 71937-11351, Iran. ${ }^{3}$ Department of Psychiatry, Shiraz University of Medical Science, Shiraz, Iran.

Received: 26 May 2020 Accepted: 19 June 2020

Published online: 18 August 2020

\section{References}

1. Wray NR, Ripke S, Mattheisen M, Trzaskowski M, Byrne EM, Abdellaoui A, Adams MJ, Agerbo E, Air TM, Andlauer TM (2018) Genome-wide association analyses identify 44 risk variants and refine the genetic architecture of major depression. Nat Genet 50(5):668

2. Picco L, Subramaniam M, Abdin E, Vaingankar JA, Chong SA (2017) Gender differences in major depressive disorder: findings from the Singapore Mental Health Study. Singap Med J 58(11):649 
3. Hedegaard H, Curtin SC, Warner M (2018) Suicide mortality in the United States, 1999-2017

4. Schaffer A, Levitt AJ, Bagby RM, Kennedy SH, Levitan RD, Joffe RT (2000) Suicidal ideation in major depression: sex differences and impact of comorbid anxiety. Can J Psychiatry 45(9):822-826

5. Ajdacic-Gross V, Weiss MG, Ring M, Hepp U, Bopp M, Gutzwiller F, Rössler W (2008) Methods of suicide: international suicide patterns derived from the WHO mortality database. Bull World Health Organ 86:726-732

6. Hao D, Yang Z, Li F (2017) A 61 Year Old man with intracranial sewing needle. J Neurol Neurophysiol 8(420):2

7. Hull KL, Denton-Beaumont R (2019) An unsuspected intracranial foreign body on the acute medical unit. BMJ Case Rep CP 12(7):e230010

8. Balak N, Güçlü G, Karaca I, Aksoy S (2008) Intracranially retained sewing needle in a child: does the rust on the needle have any implication? Eur J Trauma Emerg Surg 34(2):159-162

9. Amirjamshidi A, Ghasvini AR, Alimohammadi M, Abbassioun K (2009) Attempting homicide by inserting sewing needle into the brain: report of 6 cases and review of literature. Surg Neurol 72(6):635-641

10. Chandran AS, Honeybul S (2015) A case of psychosis induced self-insertion of intracranial hypodermic needles causing seizures. J Surg Case Rep 2015(1). https://doi.org/10.1093/jscr/rju145

\section{Publisher's Note}

Springer Nature remains neutral with regard to jurisdictional claims in published maps and institutional affiliations.

\section{Submit your manuscript to a SpringerOpen ${ }^{\circ}$ journal and benefit from:}

- Convenient online submission

- Rigorous peer review

- Open access: articles freely available online

High visibility within the field

- Retaining the copyright to your article

Submit your next manuscript at $\boldsymbol{\nabla}$ springeropen.com 